\title{
The smartphone's role in the contemporary backpacking experience
}

EVERIIN SILAS, IT University of Copenhagen

ANDERS SUNDNES LøVLIE, IT University of Copenhagen

RICH LING, Nanyang Technological University

\begin{abstract}
In this study we explore the smartphone's role in the contemporary international backpacking experience. This paper will examine backpackers' perceived changes in mediated interaction and personal attitudes towards phone use in co-present situations pretrip, on-trip, and post-trip. John Urry and Jonas Larsen's theory on tourist performances as well as Cody M. Paris et al.'s experiences of technology induced anxieties and tensions while traveling provide a conceptual framework for the analysis. A sample of 11 backpackers were interviewed at youth dormitories in Indonesia and Malaysia. Post-trip interviews were conducted primarily online through Skype. The findings suggest that there is an ideal of staying offline while traveling. Yet, backpackers report connecting daily with their smartphones and reveal a travel-time legitimacy for sharing updates and receiving attention on social media. After the trip, backpackers perceived a reduction in their own phone use and an increased tolerance for others' phone use in their presence.
\end{abstract}

\section{KEYWORDS}

Smartphone, Norms, Backpacking, Ethnography, Mobile Communication

\section{Introduction}

Traveling as a backpacker over the course of four months around South-East Asia, the first author of this paper observed a general apparent absence of smartphone use within the backpacker culture. With the media villainizing modern technology and deeming especially the youth as hopelessly addicted to the device, this observation caused the author to become curious about young backpackers' relationship with their smartphones. Did they consciously avoid spending time online? Which relations did they put on hold for the period of their travel? What was their relationship with the smartphone in their everyday life, and what were their attitudes towards others interacting with the smartphone in their presence? Did the travel-time reduction in smartphone use persist after they returned home? 
These questions awoke curiosity, and led to the study presented here.

For decades, international backpacking has been a popular form of tourism for young people. International backpackers are typically travelers between the ages of 18 and 35 (Young \& Hanley 2010), traveling over the course of several months (Sørensen 2003, O’Regan 2008), and staying at budget youth dormitories instead of hotels (Welk 2004). The act of backpacking has become significantly easier than it was in its early 'beatnik' and 'hippie' days in the 1950s-1970s (Paris 2009). Cheaper air-fares, the expansion of guidebooks, the increasing availability of backpacker accommodations, -transportation, and -travel agencies, as well as higher disposable income, and the increased representation of backpacking in pop culture have all contributed to the increase in backpacking tourism (Paris 2009). More recently, the adoption and use of smartphones and internet connectivity in all corners of the world has also contributed to making this type of travel easier (Wang, Xiang, Fesenmaier 2014).

Several authors have pointed out that in spite of recent developments in communication technologies and connectivity, contemporary backpackers still pursue an 'authentic' backpacking experience to resemble that of the hippie days, focusing on interacting with the local culture instead of mediated interactions (Welk 2004, Haldrup \& Larsen 2010, Burns \& O’Regan 2008). Backpackers tend to believe that technology distracts them from co-present travel experiences and face-to-face interactions (Hannam, Butler \& Paris 2014, Molz \& Paris 2013). Indeed, Jennie G. Molz and Cody M. Paris argue that backpackers resist mediated contact, even devising strategies to 'elude their social networks' (2013, 190). Paris et al. add that 'For some travelers, being disconnected (even unexpectedly) can be beneficial or perceived positively as the often overused excuse "I can't be reached" is actually true' (Paris et al. 2015, 807).

There is a tension however. Backpackers carry with them internet-use habits from 'back home' that influence use during the trip (Paris et al. 2015, Urry \& Larsen 2011, Haldrup \& Larsen 2010). Because of the general availability of the internet (Wang, Xiang, Fesenmaier 2014), and because backpackers always have their personal internet-accessing devices with them (Ibid.), it is difficult for these young people to purposefully disconnect. In addition, the people 'back home' (e.g. parents, boy/girl friends, etc.) have learned to expect updates on a regular basis (O’Regan 2008, Paris et al. 2015). As a result, the internet and mobile communication is reshaping the 'authentic' backpacker experience. These developments illuminate the tensions between the traditional backpacking ideal of being 'cut off' from the world vs. modern ways of arranging travel and staying in touch with a geographically dispersed network (Paris 2009).

In this study, we will use interviews with a small sample of backpackers regarding their attitudes towards smartphone use before, during and after their travels to answer the 
following research question: How do contemporary backpackers perceive the role and the influence of smartphone use on their backpacking experience, and how is the backpacking experience seen to influence backpackers' attitudes towards smartphones after they return home?

In parallel to the fast technological developments, several scholars have warned about people's dependency on smartphones. Philip Pearce and Ulrike Gretzel (2012) and Sherry Turkle (2011) claim that technology- and internet dependency is connected with people's sensory reactions to communication devices. Jan van Dijk (2012) comments that what is nailing people in front of their screens, is the feeling that life is happening elsewhere and in order to not miss out on it, they need to be there through their phones. The theme of smartphone dependency is also discussed in tourism studies (Paris et al. 2015, O'Regan 2008).

\section{Smartphone use and the backpacking experience}

Much research has been conducted to shed light on the role of smartphones in society, including social norms and ideals regulating their use (Ling 2004, 2008). Judgments about appropriate use vary widely and Jeffrey Hall, Nancy Baym, and Kate Miltner point to a general concern that smartphone use hurts co-present interaction: 'There is a moral panic that the increasingly pervasive use of smartphones is damaging relationships' $(2014,135)$. Sherry Turkle claims that smartphone use may have a negative effect on people's copresent social skills. Turkle writes that 'Digital life cheats people out of learning how to read a person's face and their nuances of feeling' (2011, 271). Troels Fibæk Bertel (2013) adds that since the smartphone gives people informational freedom, it is no longer acceptable to waste others' time by asking them something one could look up on their own, resulting in missed opportunities to socialise.

Circulating widely in media, the topic of smartphone dependency has also become a research interest of scholars. Philip Pearce and Ulrike Gretzel (2012) claim that technologyand internet dependency is connected with people's sensory reactions to the sounds coming from the phone. Turkle also examines this theme. She notes, 'Our neurochemical response to every ping and ring tone seems to be the one elicited by the "seeking" drive, a deep motivation of the human psyche. Connectivity becomes a craving, when we receive a text or an email, our nervous system responds by giving us a shot of dopamine. We are stimulated by connectivity itself' (2011, 227). Jan van Dijk (2012) argues that what is nailing people in front of their screens is the feeling that life is happening elsewhere, and in order to not miss out on it they need to be there through their phones.

The theme of smartphone dependency is also discussed in tourism studies as traveltime 
challenges with connecting due to power cuts and 'dead zones' reflect a contrast with young western backpackers' experiences of near-constant connectivity back 'home' (Paris et al. 2015, Pearce \& Gretzel 2012). Paris et al. (2015) note that the challenges of staying connected while traveling result, for some, in a recognition of their otherwise excessive technology use. For these people, the travel-time limitations of digital connectedness represent an opportunity for remedy. The authors note that 'some tourists are now choosing to be "unplugged" while traveling, seeking an escape from "connectedness" and, in a sense, therapeutic rehabilitation' (Paris et al. 2015, 804). They also comment that the popularity of this behavior has created a new market segment, namely the "“digital escaper" market, where guests are asked to give up their technological devices’ (812).

John Urry and Jonas Larsen further argue that there is an idealisation of an authentic tourist experience, which is similar to pilgrimages. They note that 'Like the pilgrim, the tourist moves from a familiar place to a far place and then returns to the familiar place. At the far place both the pilgrim and the tourist "worship" shrines which are sacred, albeit in different ways, and as a result gain some kind of uplifting experience' (Urry \& Larsen 2011, 22). Instead of viewing this 'sacredness' as something religious, the authors describe it as the anticipation of experiencing pleasures from escaping the daily routine and work schedules at home. They elaborate that this anticipation is something that is shaped by visual and narrative depictions of the authentic travel experience from various media, and travelers' own expectations of their role. The backpackers with whom we spoke also noted that an 'authentic' experience, possibly sans smartphone, had similar dimensions.

The presence of smartphones may be both a tool and an obstacle for the kind of 'sacred' experience described by Urry and Larsen. There is clearly a tension here. On the one hand, communication technology makes travel easier. It helps travelers to plan and manage their trip. It serves as a camera, a notebook, a source of information (weather, flight/bus/ferry information, local attractions), a tool with which to manage reservations, etc. an entertainment device (music, reading stuff, video), a map, a link to other backpackers, and to people back home (Wang, Xiang and Fesenmaier 2014). At the same time it is also seen as disturbance in the pursuit of 'authenticity'. Paris finds that since backpackers are increasingly equipped with portable internet-accessing devices, they have a strong need to be 'fully integrated and maintain a sustained state of co-presence between the backpacker culture and their home culture' (2009, 1-2). However, he comments that removing the gap between home and away decreases 'the "authentic" experience of off-the-beaten-track travel' (Paris 2010, 36). In addition, since it facilitates connectivity, the smartphone also increases backpackers' temptation to 'to fill downtime with technology vs. real world experiences' (Paris et al. 2015, 811). To feel more 'in the moment', some backpackers choose to 'reject technology whilst travelling in the spirit of "dropping out" for a time' (Young \& Hanley 2010, 4). 
It is the tension embodied in the smartphone that is of interest. We are interested in examining how contemporary backpackers balance the need for connectivity with the pursuit of the 'authentic' travel experience.

\section{Method}

The backpackers' experiences in this study were gathered through localised ethnographic interviews (Spradley 1979) conducted in Indonesia (Bali) and Malaysia (Kuala Lumpur, Perhentian Kecil) by the first author while she was also participating in the backpacking culture. Because of a geographically dispersed sample, the follow-up interviews were collected via Skype. Sixteen semi-structured interviews were conducted with a sample of eleven backpackers over the course of five months - from March to July 2015. The aim with these interviews was to understand the smartphone's role in backpackers' everydayand travel activities and examine how the backpackers carried their travel experience into their everyday lives after they had returned home.

The initial interviews were designed to document the informants' experiences with mediated and co-present interaction in their daily life while traveling, and to also record their reported phone use behaviour and -attitudes prior to the trip. To start out, the informants were asked about specific memories of their most recent dinner situation, and prompted to describe the phone's role in that setting. Progressively, they were asked about general beliefs, motivations and values regarding smartphone use during travel and when they were 'back home'. In this phase, there were interviews with eleven informants and these lasted between 22 minutes and 1 hour, 39 minutes. Most of the interviews took place at youth dormitories. One was recorded at a restaurant, and one at an airport.

The second phase of the research took place between three weeks and two months after the informants had returned 'home'. The follow-up interviews, done via Skype, focused on the informants' phone use and -attitudes after the trip. The informants' descriptions of their mediated relations and phone interactions in co-present situations were supplemented by them reviewing their recent interactions on their preferred smartphone-based communication platform. While all of the informants initially agreed to participate in follow-up interviews, only five of them found time to do so in time for the project's deadline. The post-trip interviews lasted between 21 minutes and 1 hour, 6 minutes. The resulting material was transcribed. The material was then examined for themes that were common across some or all of the interviews. The findings presented below arose out of this analysis.

The informants included seven women and four men in ages between 19 - 34 years. All of the eleven informants participating in this study were recruited at youth dormitories, which is where the first author met them while she was traveling as a backpacker to gather the 
data. The sample composed of individuals from Denmark (3), Holland (2), Germany (2), Scotland (2), England (1) and South Africa (1) and about half were below the age of 22. The interviews were conducted in English.

\section{Staying offline while traveling}

For our informants, similar to the findings in earlier research (Haldrup \& Larsen 2010, Urry \& Larsen 2011), the main purpose of the backpacking trip was to gain a contrasting perspective vis-a-vis their everyday life, and to meet new people (Young \& Hanley 2010, Anderskov 2002). Several informants said they wanted to get to know themselves better and find out what life had to offer. Trevor's (34, South Africa) 1 comment sums up these informants' expectations, 'This journey for me is a soul searching one to firstly discover who I am and what I want from life, and also I think a little bit of what life wants to give me.'

Some even expressed feelings bordering on Urry and Larsen's (2011) 'sacred' in relation to their travel experiences. Vincent (21, Germany) described a chance encounter while watching the sunset at a beach, 'That was like oh so - sometimes you just, I don't know that moment you just ask yourself "Does it mean something, or could it mean something?", In Vincent's view, getting away from everyday life also meant getting away from smartphones and the internet. 'I think it was nice, you had this reduction, you did not have [Internet] access the whole time, and I think that's the nice thing about it'. Nearly all informants, in various ways, expressed an ideal that backpacking is meant to be primarily an offline experience, prioritising physical experiences and being in the moment. According to Vincent, being online takes one away from the experience travellers go to get.

The only thing you need the internet for is having contact with the place where you are not at the moment. [...] you don't need that, what do you need that for? Like why should you go to Bali if you want to stay in contact. [...] I think it's just about being there.

Similarly, Karina (21, Denmark) found that physical experiences were more important than being online while traveling, 'It's like you are more aware of everything. You know, you're just not staring at the phone all the time. [...] you talk about what to do and just watch out the window. And do stuff instead of just watching the phone.' Sofie (20, Denmark) described how using the paper map made her feel like she noticed more things around her. 'I think you see a lot more of the city when you're not looking down [on the phone].' She

\footnotetext{
1 The names of the informants have been altered.
} 
reported a part of this positive experience having to do with it being easier to 'get lost' without a GPS. 'Sometimes we get lost and find amazing places and other times we just keep on trekking...' Klara (24, Holland) simply stated that for her, local interactions take priority over the mediated while traveling, 'If I had people to talk to, I would rather talk to people than WhatsApp.'

For several informants, the desire to avoid smartphones went together with a concern about smartphone dependency. 'I think some people are a bit too dependent on it. Like they are a bit addicted to it' (Karina). Some noted that travel has provided them a sense of control with regards the compulsion to use internet. 'It's just nice to be your own master of "I don't need it right now"' (Sofie). Several informants reported that spending an extended period with limited connectivity during travel had motivated them to try and reduce their smartphone use after they return home. This was because they saw a lot of their smartphone use as being a waste of time.

Because of the addictive nature of these devices. [...] Time just goes away [...] - that's what bugs me the most about using the devices, because when you think you're going to spend five minutes looking for something, it takes much longer than it's supposed to. (Trevor).

For some informants, the desire to stay offline was connected with a general concern regarding the attrition of people's co-present social skills. They commented that online communication platforms, especially dating sites, removed the confidence needed to meet people.

It's problematic because it's taken the social aspect of going out and meeting somebody and the confidence that you need to be able to do that [...] Technology becomes a barrier where you don't have to show your true self. (Trevor).

As a result, the informants noted that they experienced people in their everyday life becoming less socially skilled and feeling more awkward and insecure when meeting people in the physical world.

This stands in sharp contrast to the backpacking experience, where the informants find it much easier to meet people. Part of the reason for being able to make friends easily while traveling is the feeling of 'sameness' - that apart from age, nationality and gender backpackers are basically spitting images of each other (cf. Sørensen 2003, Anderskov 2002). Klara commented, 
'people on the trip whom we meet are kind of the same persons that you are, as open-minded, especially when you travel alone.' She also emphasised that she did not fear a rejection when approaching strangers, 'I could go to two people, sitting at a table and say 'hello, how are you doing, can I join you? They will never tell me "No," never.'

According to our informants, socializing was easier since backpackers were less likely to have their attention turned towards their smartphones.

It will make it more easy if people were not looking at the phone, because if people are looking at the phone and have music in their ear, I think that I will feel that I'm interrupting something if I ask the person something. Because it looks like they don't want to speak to anybody. (Lise, 29, Denmark)

Being pleased with the ease of meeting new people while traveling, Myrthe (25, Holland) expressed wanting to experience more co-present interaction with strangers in her home environment without the phone 'in the way'. She said, 'I want to do more by myself like having a coffee somewhere and didn't sit on my phone the whole time but just sitting there and maybe talk to a stranger' (Myrthe).

\section{The need to go online while traveling}

In spite of expressing the ideal of pursuing an 'authentic' offline backpacking experience, all of our informants said that they logged-on to the internet every day for practical and social reasons. Even with several informants bringing a laptop or a tablet along on their trip, they all resolved to only using their smartphones for accessing the internet. This was due to the phone always being on them, and with uses extending beyond internet access. These included using it as a GPS, as a calendar, as a notebook for writing down the names of people they met on the road to later add them on Facebook, and as a camera. For close to all of the informants the phone was the primary camera on the trip.

To log-on to the internet, WiFi access was used since almost none of the informants reported having mobile data subscription with an operator at the time of the interview. Several informants commented on having to spend a considerable amount of time every day finding a restaurant with good WiFi. Ironically, rather than being Ray Oldenburg's (1989) 'third places', that is a space for co-present interaction, these cafés became a space for mediated interaction. 
When in WiFi zones, reportedly between five minutes and two hours a day, the backpackers described primarily staying in touch with their worried parents whom they had taught to use their preferred communication platforms prior to their trip. In this, the informants allowed their parents to perform 'remote parenting' (Rakow \& Navarro 1993), while also indicating personally needing the contact to the 'safe home'. Karina described understanding her parents' need to do some parenting over distance: 'Yea, they're just like, [...] "oh, sounds so good, be safe". [...] [They] try not to be too much. But they can't help it.'

Some of the informants reported trying to decrease the time spent online by minimizing one-to-one mediated interactions and instead posting semi-public updates on their Facebook or Instagram pages. Trevor explained how social media can help with travel-time loneliness, providing a sense of constancy and connection to home.

I think in meeting so many people in the last couple of weeks and being sort of a nomad for these three weeks so far, there can be a sense of loneliness and you sort of turn to the technology to find comfort or companionship or familiarity because Facebook doesn't change based on the country that you are in. You'll still see the same friends that you used to see before, posting things up.

While the informants indicated being bothered by having to reply to messages, their continuous behaviour of semi-public broadcasting indicates that they have a significant need to feel included in the life back 'home.'

Despite reporting an ideal for being offline while traveling, the informants indicated that travel gives them a special legitimacy for self-exposure, which they reported not having back 'home'. Several of the informants emphasise that in their everyday life, Facebook is not for posting things, but rather for watching others. 'I've never been big on posting. I'm not that good at putting myself out there. So I'm more like, watching what other people do' (Karina). However, while traveling, most of the informants regularly posted updates and photos on Facebook and Instagram. Myrthe, who reported not using Facebook in her everyday life revealed that while traveling, she posted regular updates to all of her friends, 'I use Facebook so my neighbor can see it and a teacher from high school and also I know that they like to see what I'm doing now in my life.' They explain this by wanting to reduce the time and effort they put into maintaining their relations back home. In addition, posting photos and updates from exotic corners of the globe serves a similar function to post cards. It updates the people at home of their situation and it also burnishes their status as a traveler. 


\section{After the trip: Reduction in own use, increased tolerance for others' use}

The second part of our research question examined how the backpacking experience influenced the informants' attitudes towards smartphone use after they returned home. Our informants reported somewhat contradictory experiences. Some said that the backpacker experience had led to a reduction in own use. Lise described feeling like she had become lazier at answering messages.

I think I'm very lazy with my phone now, it's just I had a text message from my friend yesterday she said 'are you not looking at your snaps?', [...] 'because I sent you a snap very, very long with big letters, capital letters, long time ago.

Vincent had no doubt that his phone use had decreased. His iPhone was stolen in Bali and the replacement he bought during his trip could not connect to mobile data in Germany. Yet, he said he did not mind the reduction and was not in a hurry to buy a new smartphone.

Echoing Lise (noted above) that limiting phone use facilitated establishing social contact, Vincent said that he no longer used his phone when with friends. He said, 'I'm very...I hate that, so I don't do that anymore.' Similarly, Klara described reducing the number of people with whom she interacts since she did not want to spend the entire day on her phone. She said, 'I think it's annoying to keep in contact with everybody. I don't want to be on my phone all day.'

Interestingly, and perhaps ironically, informants also reported having become more tolerant towards other people's use of smartphones in their presence. This stands in clear contrast to their attitudes towards co-present smartphone use during the initial on-trip interviews, where close to all of the informants said that they were very sensitive about this type of use in their everyday life. They had various strategies with which to limit co-present use, e.g. the 'phone stacking game', in which the first person to touch their phone was punished, often having to buy the table a round. Informants also reported insisting that their friends leave their phones in another room during social interaction, or at least not have it on the table.

Sometimes we have a rule that we put the phone down to be together so we don't sit with it all the time. [...] It's nice to just talk and not just sit with your phone... you can do that all the time when you are alone so. (Karina). 
Many had personal rules with regard to using their device. Lise mentioned that she only had the ringing 'sound' on when she was expecting a call. In this way she avoided a potentially awkward situation when she felt that a call would come in the way of 'really' being together.

However, in their post-trip interviews, the same informants reported that after the trip they felt more relaxed about other people interacting with the smartphone in their presence. Before the trip, Lise would ask her friends to take their phones off the table when they met. After the trip, she did not have this need any longer, 'All of my friends, maybe it also includes me, when we're having dinner now the phone is on the table.' And Karina, who had similar views, in her post-trip interview, said 'it's okay, I think it's still a bit annoying if it's [being used] all the time.' She explained this shift in opinion as taking others' behaviour less personally, '[if] they want to text, [then] they want to text.'

As Leysia Palen, Marilyn Salzman \& Ed Youngs (2000) as well as Maaike Geerdink (2014) argue, a personal mobile phone experience can increase one's tolerance for other users. This appears to be true for some of our informants, who describe both having become more familiar with their smartphone and more tolerant of others' co-present smartphone use. These informants had previously (before the trip) primarily used laptop computers for online communication. However, traveling without a laptop forced them to rely solely on their smartphone. Lise notes this when she says, 'Maybe I will use my phone more when I come home than before, because on this trip I really learned how to use my phone.' Myrthe also found that travel forced her to learn.

Before I [went] on this trip I didn't do that a lot and I'm not very good in it but now I talk to a lot of people about apps and I have downloaded apps and now I use it and I'm thinking yeah it's very easy.

The resulting increase in their use, and familiarity with their smartphones may be part of the reason why some informants report being more accepting of other people's smartphone use after their trip.

In addition, in her post-trip interview, Klara explained that her experience as a backpacker made it easier for her to empathize with her peers' need to be in mediated contact. She explained that during her travels it was often difficult to predict the next time that there would be internet access. In her mind, this legitimated smartphone use even when together with others. Interestingly, she said that this increase in co-present tolerance persisted after her trip, '[It is] still annoying. But it depends, if I'm with my colleagues and I don't see them much, yeah, I don't care. I understand. That's the same for people I travelled with.' 
Thus, the durability of the informants' smartphone based attitudes varied. In some cases, such as that of Vincent who did not have mobile internet access after returning home, his resistance against mediated interaction had lingered. In other cases, such as Karina, Lise and Klara, they had accepted the intrusion of the mobile phone into social situations.

\section{Discussion}

The interviews with our informants reveal the smartphone to be a disturbing element in backpackers' attempts to achieve an 'authentic' backpacking experience. It is the locus of a tension between their ideals of staying offline while traveling, while still needing to go online for practical and social reasons. While backpackers said that travel was about being in the moment, they make considerable efforts to connect daily with their smartphone. This perhaps reflects them being accustomed to managing travel practicalities online.

Further, the smartphone is reported to be an irreplaceable tool for calming the concerned family members back home. The issue of having to stay in touch with parents might be especially sensitive in this study due to most of the informants having been in their early 20s, and several of them still living together with their parents prior to their trip. Just as Rich Ling $(2007,2008)$ describes preteens using the phone as a 'vicarious umbilical cord' (2008, 14), the smartphone seems to have become the 'umbilical cord' between our traveling informants and their parents. In that, the smartphone also puts travellers under a greater obligation to be online and allow their parents to have a sense of 'remote parenting' (Rakow \& Navarro 1993) opportunities. The backpackers are likely see online connectivity as a way to stay in touch with those back home and as a cure for their travel-time loneliness. All of this is perhaps a commentary as to how the mobile phone is increasingly structured into our lives.

Yet, as with pilgrimages, there is the goal of achieving what Urry and Larsen (2011) call sacred inner experiences away from mundane life. Backpackers seek to fill their time with meaningful travel experiences. This supports Urry and Larsen's (2011) argument that the perceived sacredness of objects is based on the tourist's anticipation of seeing something new or something different. Since an 'authentic' backpacking experience was seen as being transformative as well as being offline, some of the informants took pride in their reduced post-trip smartphone use. Through a perceived reduction in its post-trip use, the smartphone becomes an element in the backpackers' anticipated transformational narrative. Namely that the travel experience changed their life for the better.

The informants' increased tolerance after the trip can also be understood as a result of their experiences with co-present smartphone use in various public spaces. As earlier research into social norms regulating phone use has shown, there has been a strong norm against using one's phone in certain kinds of spaces and situations, in particular in places like 
restaurants and cafés (Ling 1996, 2008). Contemporary smartphone usage such as checking messages, updating social media etc. may be less intrusive to the surroundings than speaking on the phone, however Geerdink has more recently found that it is still common to be concerned about other people's use of phones in spaces where there is an agreement about behavioural norms, for example restaurants (2014). 'When injunctive norms become more clear, and people are aware of the standards of behavior, people will be more willing to disapprove other people's mobile phone activities in public social settings.' (Geerdink 2014, 53). Many of our informants also said that before going on their backpacking trip, they would typically find it unacceptable to use their smartphone in this kind of situation. However, when backpacking, this was to some degree turned on its head. During travel the informants sought WiFi access in these spaces and used them for mediated- rather than copresent sociation. Sometimes they even become de facto 'office spaces' for travelers using the internet to organize their travel and to manage their connections with friends and family back home. Thus, during their backpacking, another norm of use was adopted regarding smartphone use in public spaces.

This paper provides a view of of the smartphone's role in the contemporary backpacking experience. It is important to note that our informants represent a particular class of relatively privileged, young people from developed countries who are able to spend significant amounts of time and money on travel. In addition, they own advanced devices that facilitate internet connectivity. Their experiences pose a sharp contrast to that of the majority of people in the countries they are visiting, and indeed most of the world's population. Nevertheless, the results of this study shed light on some tendencies in the smartphone's role in the experiences of this privileged group of travellers. In future research, the role of the smartphone in the modern backpacking pilgrimage might be further explored through observational studies, documenting smartphone use over time, collecting actual smartphone use data, and exploring documented behaviours in interviews. The story backpackers tell their friends about their experience after the trip could also provide an interesting insight into backpackers' efforts to live up to ideals for a 'sacred' or 'authentic' experience, and the smartphone's role in that experience. 


\section{References}

Anderskov, C. (2002) Backpacker Culture: Meaning and Identity Making Process in the Backpacker Culture among Backpackers in Central America, Århus University

Bertel, T.F. (2013) “'It's like I Trust It so Much That I Don't Really Check Where It Is I'm Going before I Leave": Informational Uses of Smartphones among Danish Youth,' Mobile Media \& Communication 1, 3, 299-313

Burns, P.M., O'Regan, M. (2008) 'Everyday Techno-social Devices in Everyday Travel Life: Digital Audio Devices in Solo Travelling Lifestyles', in P.M. Burns and M. Novelli (eds), Tourism and Mobilities: Local-Global Connections, CAB International, 146-186

Geerdink, M.G.M. (2014) Towards a more pleasant social atmosphere: Not with your Smartphone but with each other : An investigation of the relation between own mobile phone Behavior and Acceptance of the use by others in Public Social Settings, University of Twente

Hall, J.A., Baym, N.K, Miltner, K.M. (2014) 'Put Down that Phone and Talk to Me: Understanding the Roles of Mobile Phone Norm Adherence and Similarity in Relationships', in Mobile Media \& Communication, 2(2), 134-153

Haldrup, M., Larsen, J. (2010) Tourism, Performance and the Everyday: Consuming the Orient, London: Routledge

Hannam, K., Diekmann, A. (2010) 'From backpacking to flashpacking: developments in backpacker tourism research', in K. Hannam and A. Diekmann (eds), Beyond backpacker tourism: Mobilities and experiences, Bristol: Channel View Publications, 1-7

Hannam, K., Butler, G., Paris, C.M. (2014) 'Developments and Key Issues in Tourism Mobilities', in Annals of Tourism Research, 44, January, 171-185

Ling, R. (1996) "One can talk about common manners!" The use of mobile telephones in inappropriate situations, Kjeller, Norway: Telenor Research and Development

Ling, R. (2004) The mobile connection: The cell phone's impact on society, San Francisco: Elsevier

Ling, R. (2008) New Tech, New Ties How Mobile Communication Is Reshaping Social Cohesion, Cambridge, London: The MIT Press

Molz, J.G., Paris, C.M. (2013) 'The Social Affordances of Flashpacking: Exploring the Mobility Nexus of Travel and Communication', in Mobilities, 2015, 10(2), London: Routledge, 173-192

O'Regan, M. (2008) 'Hypermobility in Backpacker Lifestyles: The Emergence of the Backpacker Café', in P. M. Burns and M. Novelli, Tourism and mobilities: local-global connections, CAB International, 109-132

Oldenburg, R. (1989) The Great Good Place: Café, Coffee Shops, Community Centers, Beauty Parlors, General Stores, Bars, Hangouts, and How They Get You through the Day, New York: Paragon House Publishers 
Palen, L., Salzman, M., Youngs, E. (2000) 'Going Wireless: Behavior \& Practice of New Mobile Phone Users', in CSCW '00 Proceedings of the 2000 ACM conference on Computer supported cooperative work, 201-210

Paris, C.M. (2009) 'The Virtualization of Backpacker Culture', [Conference] Information and Communication Technologies in Tourism, ENTER 2009, Proceedings of the International Conference in Amsterdam, The Netherlands, 2009

Paris, C.M. (2010) Understanding the Virtualization of the Backpacker Culture and the Emergence of the Flashpacker: A Mixed-Method Approach, Arizona State University

Paris, C.M., Berger, E.A., Rubin, S., Casson, M. (2015) 'Disconnected and Unplugged: Experiences of Technology Induced Anxieties and Tensions While Traveling', in I. Tussyadiah and A. Inversini (eds), Information and Communication Technologies in Tourism, Springer International Publishing, 803-816.

Pearce, P., Gretzel, U. (2012) 'Tourism in technology dead zones: Documenting experiential dimensions', in International Journal of Tourism Sciences, 12(2), 1-20

Rakow, L.F., Navarro, V. (1993) 'Remote mothering and the parallel shift: Women meet the cellular telephone', in Critical studies in mass communication, Vol. 10, 144-157

Sørensen, A. (2003) 'Backpacker ethnography', in Annals of Tourism Research, 30(4), 847-867

Spradley, J.P. (1979) The Ethnographic Interview, New York: Holt, Rinehart and Winston

Turkle, S. (2011) Alone together - why we expect more from technology and less from each other, New York: Basic Books

Urry, J., Larsen, J. (2011) The Tourist Gaze 3.0, London, California: SAGE

Urry, J. (2007) Mobilities, Massachusetts: Polity Press

Van Dijk, J. (2012) Network Society 3rd edition, London: SAGE Publications Ltd.

Wang, D., Xiang, Z., Fesenmaier, D.R. (2014) 'Smartphone Use in Everyday Life and Travel', in Journal of Travel Research 2016, Vol. 55(1), 52-63

Welk, P. (2004) 'The Beaten Track: Anti-Tourism as an Element of Backpacker Identity Construction', in G. Richards and J. Wilson (eds), The Global Nomad: Backpacker Travel in Theory and Practice, Clevedon: Channel View Publications, 77-91

Young, T., Hanley, J. (2010) 'Virtual Mobilities: Backpackers, New Media and Online Travel Communities', in The Australian Sociological Association 2010 Conference (TASA 2010). TASA 2010 Conference Proceedings: Social Causes, Private Lives, Sydney 6-9 December, 2010 
Everiin Silas has a Master's degree from the IT University of Copenhagen. She made the study of young backpackers' perceived changes in mediated interaction and personal attitudes towards phone use in co-present situations pre-trip, on-trip, and post-trip as a part of her Master's thesis.

Email: everiinsilas@gmail.com

Anders Sundnes Løvlie is an assistant professor at the IT University of Copenhagen. His main research interests are locative media, communication design and online debate. He is currently the coordinator for the Horizon 2020 funded project GIFT (gift.itu.dk).

Rich Ling is the Shaw Foundation Professor of Media Technology, at Nanyang Technological University, Singapore. He also works closely with Telenor Research and has an adjunct position at the University of Michigan. He has written extensively on the social consequences of mobile communication. 